\title{
Biology of the Neonate
}

\section{Foreword}

It is a great privilege for Biology of the Neonate to have been chosen to publish the proceedings of the conferences held by the leading specialists in neonatology, particularly those concerned with the subject of brain damage in the newborn child. For easily understandable practical reasons, it was unfortunately not possible to gather together the proceedings of all the conferences in a single issue. The proceedings of the other conferences will be published later in future issues.

As editor in chief of this review for the last 20 years and neonatologist for the last 37, it is my pleasant duty to introduce the principal protagonists of this meeting, particularly Rodolfo Bracci and Giuseppe Buonocore of the Università degli Studi di Siena, two research workers who, for 30 years, have done so much to promote this difficult field of research on 'the cerebral sequelae' of abnormalities in pregnancy and birth.

'A tout Seigneur, tout honneur', as the French say. There being no exact English equivalent, the nearest would perhaps be 'give credit where credit is due!' Indeed, Rodolfo Bracci was among the first to elucidate details of the oxygenation mechanisms in the fetus and the newborn child. In 1970, Rodolfo Bracci and others published 'Hydrogen peroxide generation in the erythrocytes of newborn infants' in Biology of the Neonate. In 1981, again published in Biology of the Neonate, Bracci directed a magnificent work on 'Fatty acid pattern of the erythrocyte lipids and plasma vitamin $\mathrm{E}$ in the first days of life'.

Without going into a detailed history of this essential aspect of fetal oxygenation and the disturbances of its physiology during birth, it seems nevertheless right to cite the work of Maria Delivoria, who, after having elucidated the details of the gas exchanges of fetal haemoglobin, during sojourns in Toronto and Denver, undertook a difficult and often thankless project on the cerebral sequelae of hypoxia-ischaemia at the University of Philadelphia. Ever since 1985, her group certainly has been the most prolific in the Western world, producing between 22 and 26 abstracts at the APS-SPR meetings each year, in addition to numerous original publications in the most prestigious reviews.

The 1980s saw the arrival of young intelligent and dynamic researchers who, in bringing the work of their precursors to fruition, allow the highest hopes for the future of perinatology. Three of these young researchers were very active in organizing this meeting and form part of the Editorial Board: Giuseppe Buonocore, Ola Didrik Saugstad and a young obstetrician, Felice Petraglia.

Giuseppe Buonocore is the one whom I know best and esteem for his great qualities. A faithful pupil of Rodolfo Bracci, he continues to improve our understanding of the consequences of hypoxia as much as those of hyperoxia. Several stays in Maria Delivoria's unit in Philadelphia have allowed him to make the best use of the extraordinary capacities of certain fundamental researchers of the University of Siena, particularly in the study of the protein changes in hypoxia. Thus, he and others have just published (1999) an article on 'Hypoxic response of synaptosomal proteins in term guinea pig fetuses' in the Journal of Neurochemistry. On the occasion of the retirement of Rodolfo Bracci, it was only right that his successor Giuseppe Buonocore be the principal organizer of a meeting of this quality, reviewing over 30 years of research and establishing the bases of practical applications that appear to be possible at present.

Moreover, it is this pragmatism which marks out Ola Didrik Saugstad, well known for 20 years for his work on the physiopathological con- sequences of 'oxygenation' in all its aspects. His remarkable knowledge of all the publications on the physiology as well as the pathology of this aspect of fetal and neonatal life, associated with an extreme clinical prudence, allows him to bring us all the elements concerning changes in oxygen handling at birth

The presence of Felice Petraglia completes this group effectively, in at last introducing obstetrical research capabilities. Initially the young director of a dynamic group in Udine, Felice Petraglia has traversed the world of developmental biology in Europe and on the American continent, taking an interest as much in studying the consequences of maternal stress as the physiology of the fallopian tube or the complex mechanisms of nidation and placental organization. His choice of such capable speakers allows a more complete approach to all the phenomena leading to fetal distress and premature birth, with all their consequences.

It cannot be denied that the considerable progress in these areas has resulted in a simultaneous decrease in perinatal mortality and frequency of neurological handicap. Nonetheless, perinatal asphyxia is still responsible across the world for the death of a million newborn babies and a million severely handicapped children each year. In Europe, out of 4 million births a year, 10,000 infants will suffer from cerebral palsy. The etiology of these cerebral complications is multifactorial. In addition to asphyxia at birth, which has become rare, it has been possible to demonstrate the presence of other risk factors, such as psychological stress of the mother, poor management of minor abnormalities, oxygenation birth stress, inflammation, infection and environmental events during pregnancy or even at birth, such as the pain suffered by the newborn child or the sudden separation from the mother. These last two 'birth accidents', that is, sudden and lasting separation of the newborn child from the mother and the insufficient comprehension of pain experienced by the newborn child, are doubtless the origin of postnatal neuropsychic complications that are not possible to evaluate completely. With the daily ever-increasing understanding of all these physiopathological mechanisms, it should be possible to achieve better prevention, which nevertheless turns out to be difficult, in face of the particular physiopathological features specific to each pregnancy. The aim of the EURAIBI (Europe Against Infant Brain Injury) association is to gather together the efforts of all centres of neonatology, nursing care, doctors and scientists, in order to determine the elements allowing a precise definition of these risk factors. Hopefully, these efforts will eventually lead to new preventive and therapeutic approaches.

Elements that seem to be important are the preparation for pregnancy, respect for the exceptional creative power of the woman, understanding of the extraordinary power of the fetus for recovery and even of the newborn child, all these being conditional on a good parent-child interaction, especially that between mother and child.

At a period when humankind has the impression of being able to dominate technology, it is nevertheless common sense prevention which remains the most effective means to avoid the two great causes of cerebral damage, prematurity and retardation of intrauterine growth. It is certainly this elementary prevention applied from the moment of wanting a child and the idea of the pregnancy that will assure a happy pregnancy and birth.

Jean-Pierre Relier, Paris

\section{KARGER}

Fax +4161306 1234

E-Mail karger@karger.ch

www. karger.com

\section{(C) 2001 S. Karger AG, Basel}

Accessible online at:

www.karger.com/journals/bon 